\title{
Proposal of a Test Bench for Switched Reluctance Machine 8/6 for Wind Energy Application
}

\author{
R.T. Fidelis ${ }^{3}$, G.P.Viajante ${ }^{1}$, L.C. Gomes ${ }^{2}$, D.A. Andrade ${ }^{2}$, E.N.Chaves ${ }^{1}$, M.A.A.Freitas ${ }^{1}$, C.C. Vieira ${ }^{3}$ \\ and M.J.M.Filho'
}

${ }^{1}$ Federal Institute of Education, Science and Technology of Goiás

Campus of Itumbiara - Goiás, (Brazil)

Phone/Fax number: 5564 343152005, e-mail: ghunterp@gmail.com

${ }^{2}$ Electric Drives Laboratory, Federal University of Uberlândia

Campus Santa Mônica, Uberlândia-MG, Brasil.

Phone/Fax number: 5534 3239-4411, e-mail: darizon@ufu.br

${ }^{3}$ National Industrial Learning Service SENAI

Itumbiara - Goiás, (Brazil)

Phone/Fax number: 5564 3432-2500, email: ricardotirone@ gmail.com

\begin{abstract}
This paper presents a Switched Reluctance Machine (SRM) dynamic performance analysis under various operating conditions. Thus, an SRM 8/6 was designed and built and a new bench was built to drive it, aiming to study the drive techniques and generated voltage control techniques for use in small wind turbine generators. The driving was done through a data acquisition and processing system of high performance and low cost (DSP / FPGA). The experimental results are shown and discussed.
\end{abstract}

\section{Key words}

Generator, Switched Reluctance Machine, Wind Power, Workbench.

\section{Introduction}

Currently a good portion of all the electricity produced in an industrialized nation is processed by electric motors. On generation, despite the diversity of alternative sources available, rotating electrical generator are responsible for almost all of the electricity produced. Giving unparalleled importance do electrical machines [1].

Thus, the electrical must be under constant investigation, in the search for better indices of efficiency and performance. In recent years, the development of power electronics and micro processed systems contributed to the improvement of these indexes systematically, allowing and increase in the exploitation of renewable energy sources as solar and photovoltaic.

This evolution of the electronic systems allowed the variable reluctance machine to become a strong candidate for use in wind energy applications [3], due to its intrinsic characteristics, such as: simple design, good power-to- weight ratio, high starting conjugate, ideal for applications with variable speeds [2].

\section{Constructive aspects of SRM}

Being composed primarily of a stator and a rotor with salient poles as shown in figure 1, SRM are machines simple to be designed and build, with the possibility of operation at variable of high speed, have good heat resistance and eliminate the necessity of windings in the rotor thereby reducing their manufacturing costs [3].

It is a robust and reliable machine, due to the lack of phase tolerance in polyphase machines and the possibility of performing work in environments that are under adverse conditions; presents good conjugate / volume ratio and low construction cost. [3][4][5]. The figure 01 shows a sketch of SRM.

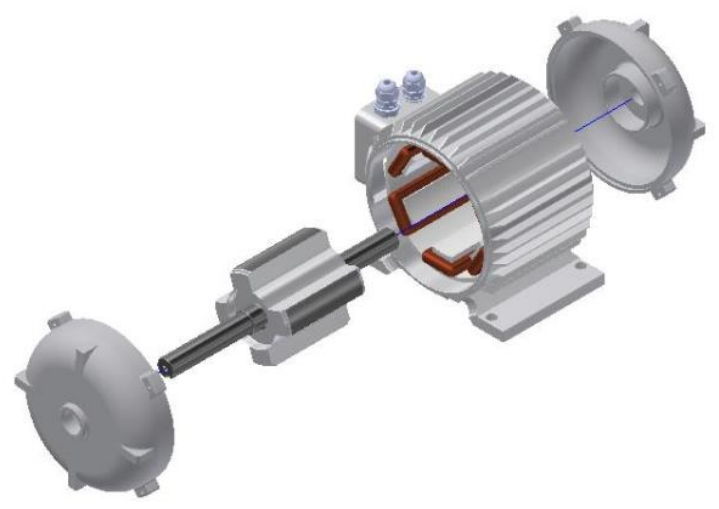

Fig. 1. Sketch of SRM

The prototype used in this work is an $8 / 6$ machine with nominal power of $2.2 \mathrm{KW}(3 \mathrm{CV})$ and rated current of $10 \mathrm{~A}$. Which was developed within the laboratory that supports 
this project from the steps concerning, the definition of measurements and materials used in the stator and rotor, mathematical and mechanical modeling, the study and dimensioning of the electromagnetic circuit, simulations, determination of the inductance curves using finite elements and finally its effective construction.

Figure 2 show a sketch of the stator and rotor of the machine built, the dimensions are shown in millimeters.

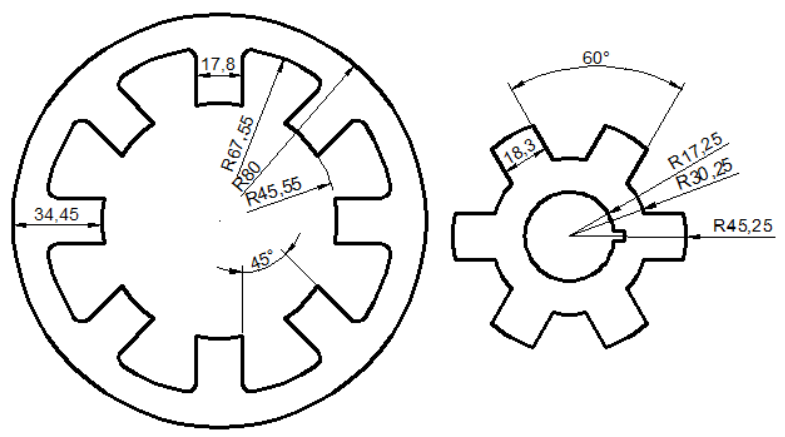

Fig. 2. Sketch of stator and rotor for a SRM 8/6.

In figures 3 it is possible to visualize the rotor and stator of the machine constructed and finished, already with the windings.

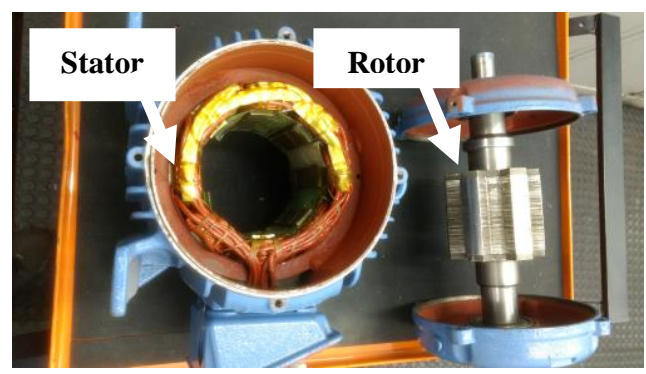

Fig. 3. Stator and Rotor of the machine.

From the physical dimensions of the machine and data on the ferromagnetic materials used, a study was carried out using finite elements in order to determine the inductances as a function of current and the positioning of the rotor in relation to the stator. Figure 4 shows a study screen made during the simulation with finite elements, demonstrating the flow density during the alignment of one of the phases of the machine [4].

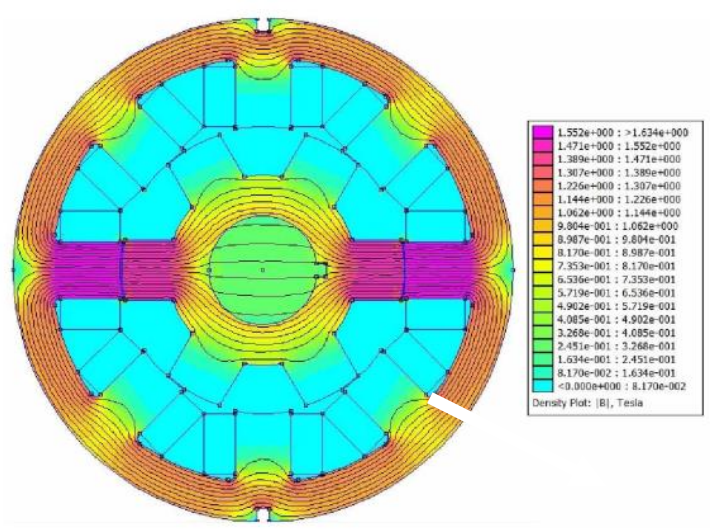

Fig. 4. SRM 8/6 flow density [4].
After the simulation with finite elements, the data were organized in tables, in order to be used later in computational models. Figure 5 shows some of the obtained curves, figure 6 shows the obtained 3D induction profile.

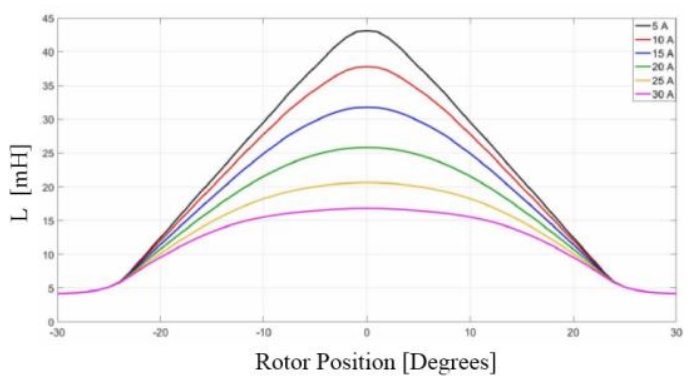

Fig. 5. Induction curves for different currents.

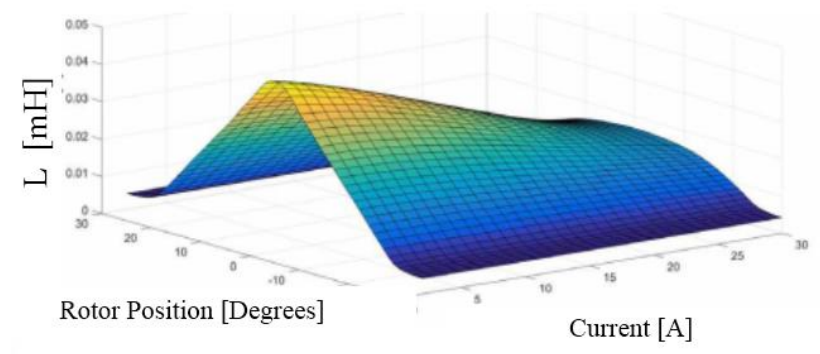

Fig. 6. 3D profile of inductance.

\section{Experimental Platform}

The SRM drive process, along with its control can become somewhat complex and confusing, as you need to perform the interconnection of multiple devices and different circuits, generally with ground distinct and isolated. In order to facilitate the tests and trials, and leave the drive SRM of didactic and simplified form, a workbench is designed to drive SRM, allowing it to be operated as a motor and generator. Figure 7 shows a simplified diagram of designed workbench.

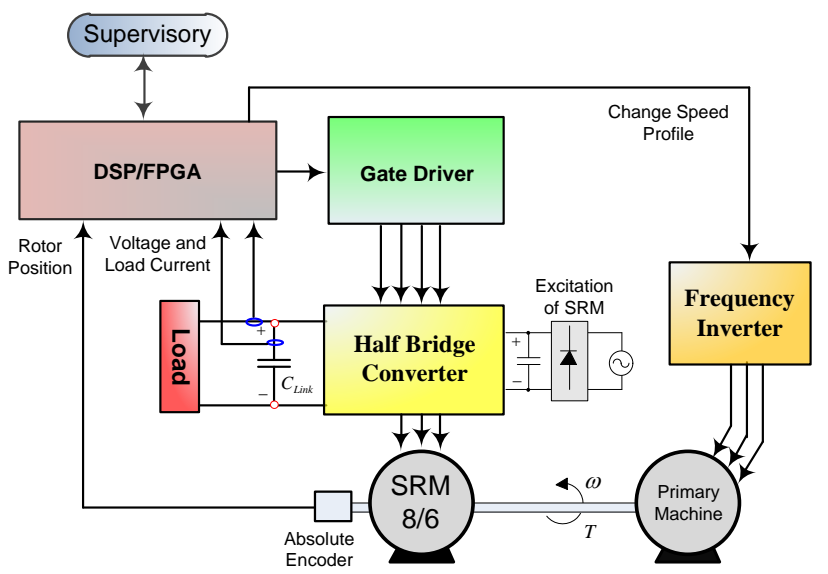

Fig. 7. Simplified diagram of designed workbench

For detecting the instantaneous position of SRM axis, was used an absolute encoder. Due to the small angular space between the alignment of one phase and the next phase in 
the machine, it was necessary to ust a 10-bit result encoder, thus allowing detection of the rotor position with an accuracy of 0.35 degrees or $0,0061 \mathrm{rad}$. For the bench was used an absolute encoder model TRD-NA1024NW; Figure 8 shows the encoder coupled to SRM

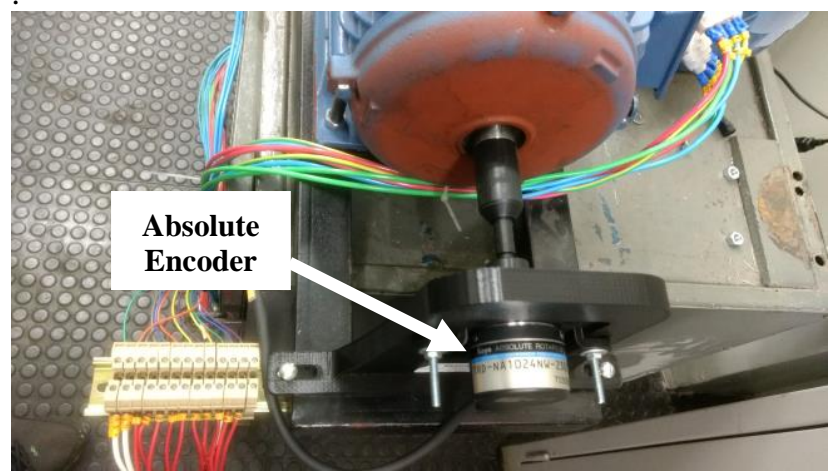

Fig. 8. Encoder Coupled to SRM.

In operation, the SRM needs a converter that provides excitement for it. The literature shows a variety of topologies of converters used for machine operation, however the most widely used due to operational characteristics is the Half-Bridge (HB) [1], [2], [3], [4], [6] and [7].

Figure 9 shows the circuit used in the converter for a single phase, others phases have a similar circuit, which is an adaptation of the converter used in [1],[2],[3],[4] for four phases and with two bus, one for excitement and other for Load.

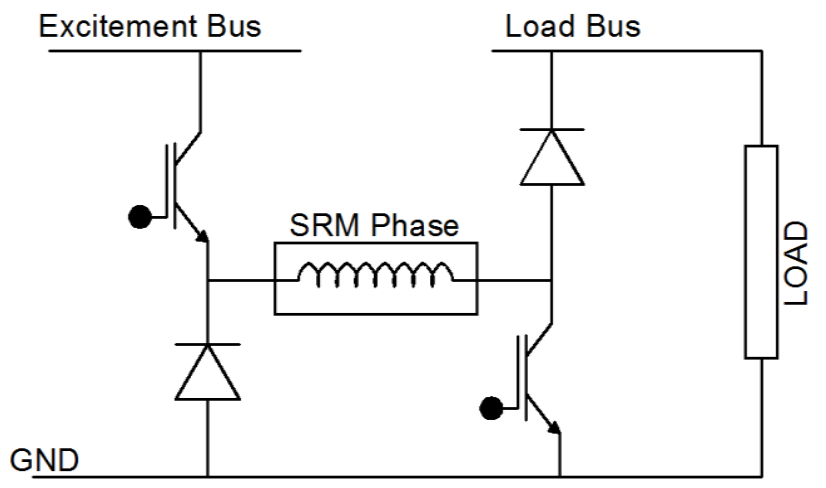

Fig. 9. Converter half Bridge adapted

To isolate and supply the pulse at the gates of the IGBTs converter keys, a driver supplied by the company "supplier ind" model DRM100D80A, thus allowing the drive independent of the eight igbts used. Having a performance similar to that drive used in [1] and [2]. with the additional possibility of setting the dead time between the trip of the keys, protection against short circuit and error detection, keeping all keys off when any errors are detected.

To perform the control and drive of the SRM it was used a DSP / FPGA device from NI Instruments "NY MyRIO". Enabling the drive by the DSP processor, the FPGA device or by a parallel configuration between these two interfaces, significantly increasing the customization possibilities of the drive and control algorithms.

\section{Experimental Results}

Figure 10 shows the photograph of the finished workbench, Table 01 identifies the workbench elements

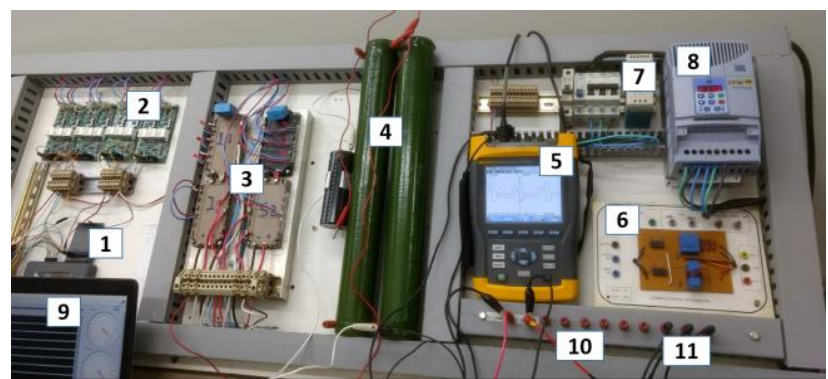

Fig. 10. Finished Workbench

Table I. - Workbench elements

\begin{tabular}{|c|c|l|}
\hline ID & AMOUNT & \multicolumn{1}{|c|}{ DESCRIPTION } \\
\hline 1 & 01 unit & NY MyRIO 1900 \\
\hline 2 & 04 unit & Isolated drive supplier \\
\hline 3 & 01 unit & Half bridge converter \\
\hline 4 & 03 unit & Capacitor and resistor \\
\hline 5 & 01 unit & Power analysis instrument \\
\hline 6 & 01 unit & Voltage/current conditioner \\
\hline 7 & 01 unit & Source for peripherals [+15/gnd/-15v] \\
\hline 8 & 01 unit & Frequency inverter \\
\hline 9 & 01 unit & Computer / Supervisory \\
\hline 10 & 08 unit & SRM out pins \\
\hline 11 & 03 unit & MIT out pins \\
\hline
\end{tabular}

Figure 11 shows Primary Machine (green), the SRM (blue) and encoder (black). As the primary machine a three-phase induction motor controlled by a frequency inverter was used, the frequency inverter is used to simulate wind speeds and profiles on the primary machine. The primary machine is a three-phase induction motor, has nominal power of $3 \mathrm{CV}, 4$ poles. $\mathrm{SRM}$ is $8 / 6$ machine with nominal power of $2.2 \mathrm{KW}(3 \mathrm{CV})$.

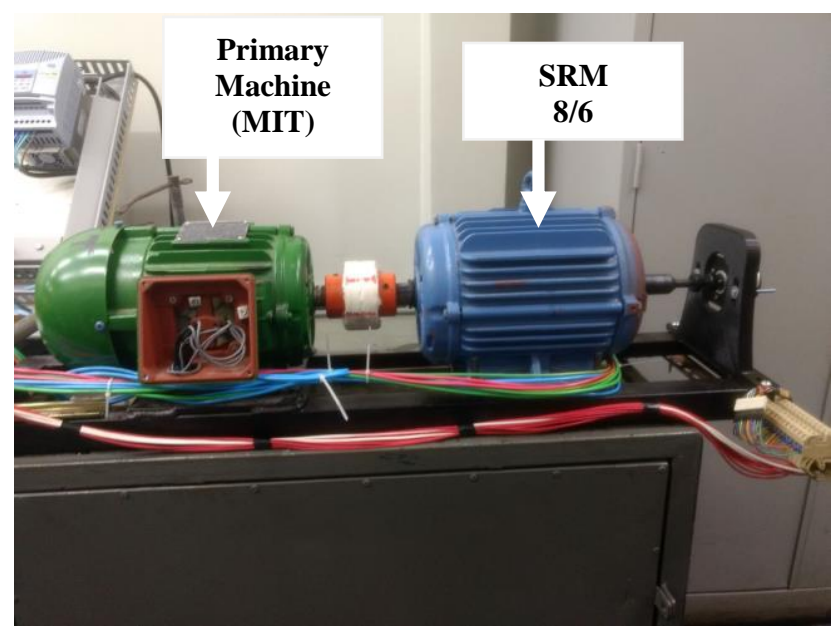

Fig. 11. SRM and MIT

Figure 12 shows one of the supervisory screens created, in this screen, it is possible to monitor the encoder inputs and output pulses to the IGBTs, it still allows calibrating the encoder zero position. 


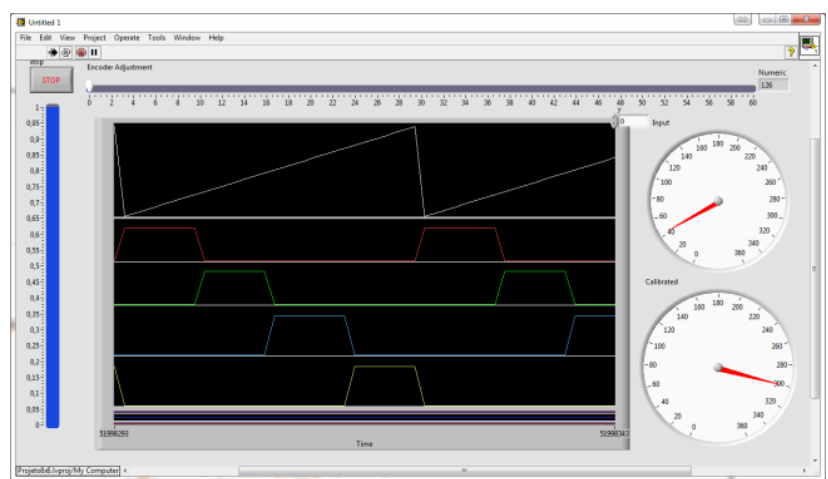

Fig. 12. Supervisory screen for encoder diagnostics.

The 8/6 machine has eight poles on the stator and six poles on the rotor, so that between the alignment of one phase and the next phase there is a lag and 15 degrees. For the preliminary drive of the machine and the tests presented here, it was decided to limit the drive angle by 15 degrees, thus avoiding the shading of the phases. However, a study will be carried out in the future on the influence of using angles of drives greater than 15 degrees.

Having an angle of 15 degrees per phase, one can understand that the cycle of activation of the four phases repeats every 60 degrees. In order to save computational resources, the input of the encoder once referenced was divided into 60-degree cycles, generating a sawtooth signal that can be seen in figure 12 . From the processing of this signal, each of the phases. Since the drive angle is shown in table 02. The parameter identified as gain is a value constant between 0 and 1 , thus allowing the pulse width to be varied by pulse off within the allowed range.

\begin{tabular}{|c|c|l|c|}
\multicolumn{5}{c}{ Table II. - Rules for pulses angles } \\
\cline { 3 - 4 } & \multicolumn{2}{|c|}{ Pulse OFf } \\
\cline { 3 - 4 } & \multirow{2}{*}{ Pulse on } & \multicolumn{1}{|c|}{ Regular } & Maximum \\
\hline A & 0 & PulseOnA+(Gain*15) & 14,999 \\
\hline B & 15 & PulseOnB+(Gain*15) & 29,999 \\
\hline C & 30 & PulseOnC+(Gain*15) & 45,999 \\
\hline D & 45 & PulseOnD+(Gain*15) & 59,999 \\
\hline
\end{tabular}

Figure 13 shows the pulses measured at the output of the drives (figure 10 , item 2 ).

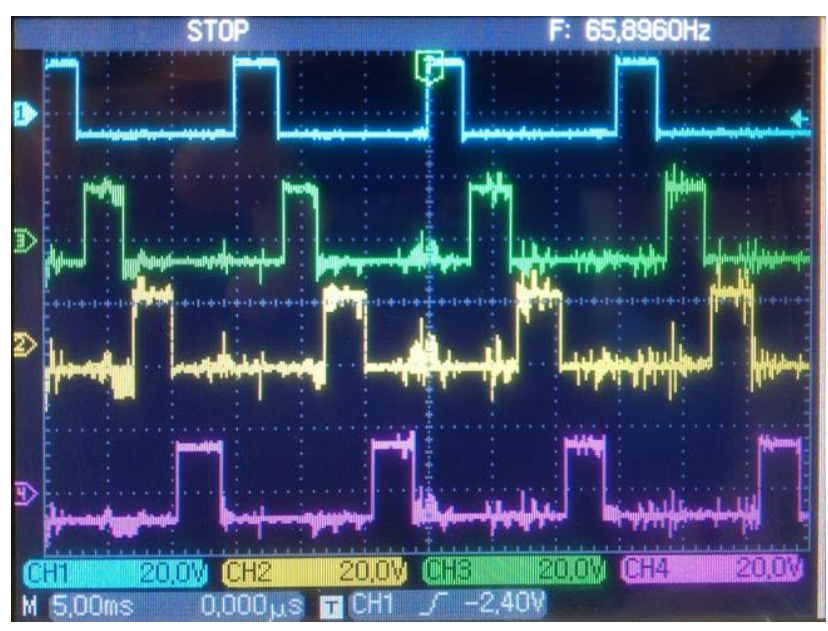

Fig. 13. Pulses in the drive (Gain=1)
The machine was preliminarily driven as a motor, for preliminary tests, the waveforms for voltage and current can be seen in figure 14 for voltage and 15 for current.

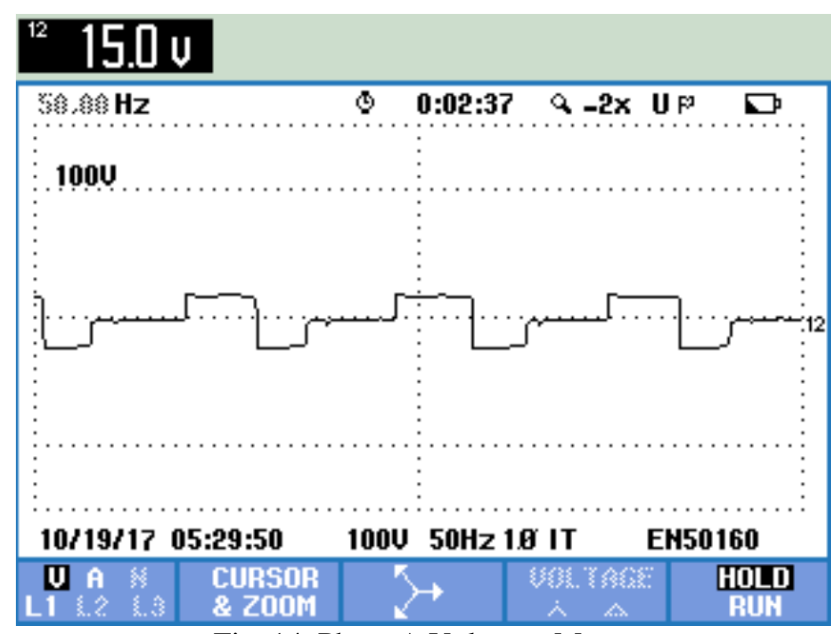

Fig. 14. Phase A Voltage - Motor

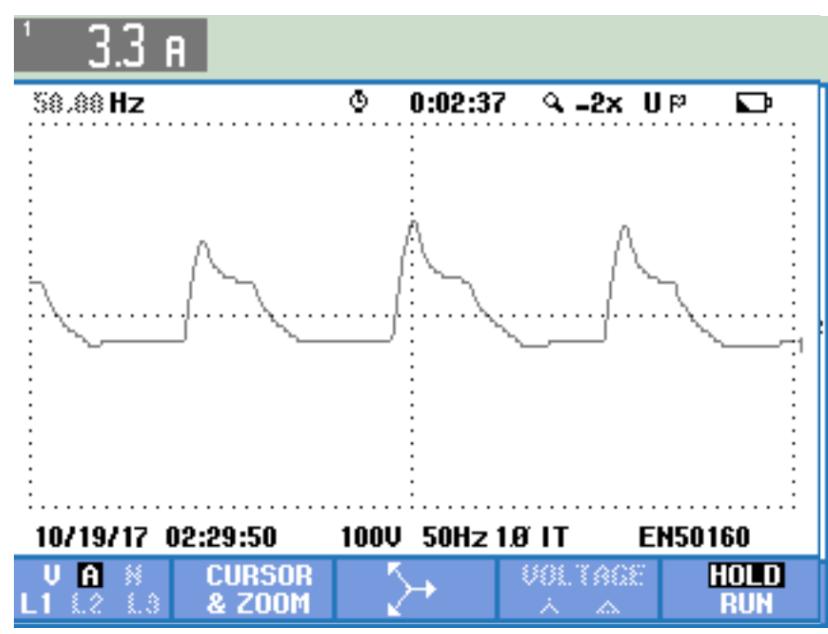

Fig. 15. Phase A Current - Motor

The machine was drived as a generator, the waveforms for voltage in the phase, current in the phase and voltage in the load can be seen in figures 16,17 and 18 respectively.

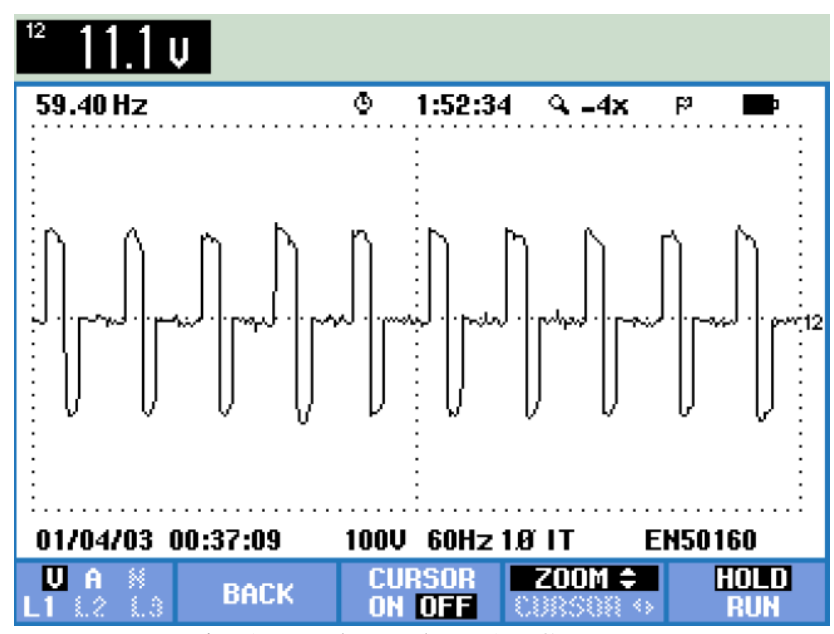

Fig. 16. Voltage phase A - Generator 


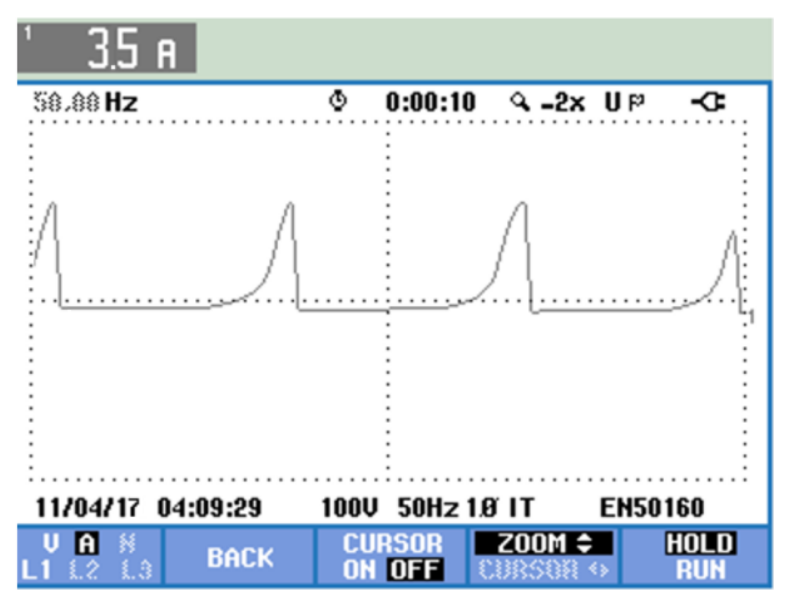

Fig. 17. - Current phase A - Generator

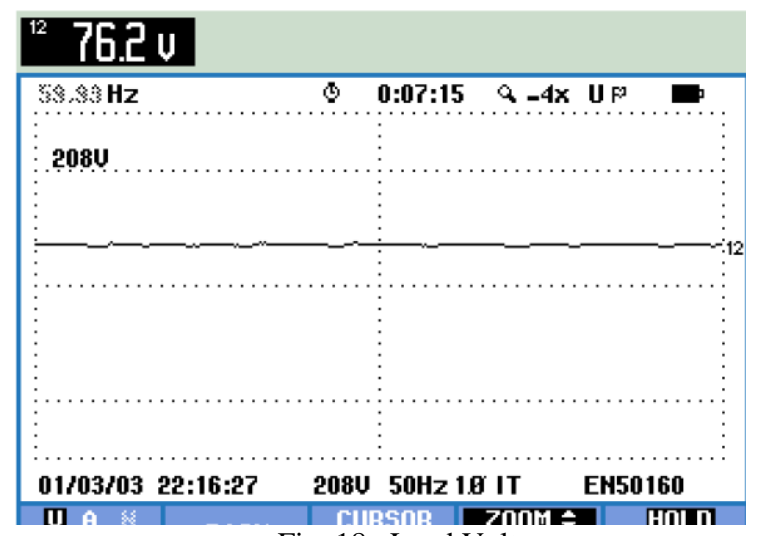

Fig. 18. Load Voltage.

Tests was made by varying the excitation voltage and pulse width on the IGBTs, all tests were done at 700 RPM on the primary machine and fixed load at $75 \Omega$, Figure 19 shows the values obtained considering the variation of the pulse width of the converter keys. Figure 20 shows the same curves considering the variation of the excitation voltage.

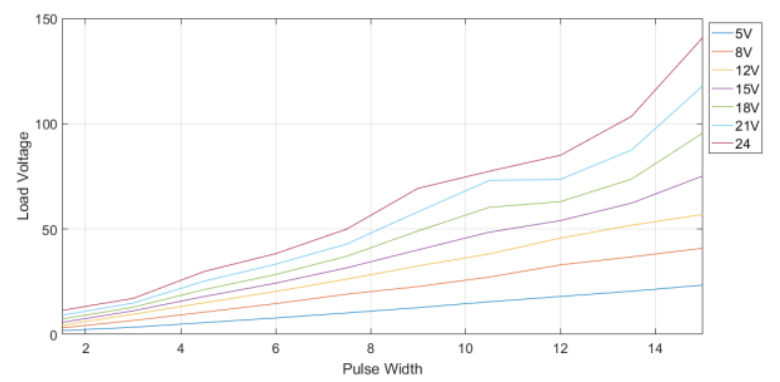

Fig. 19. Generated Voltage with pulse width variation.

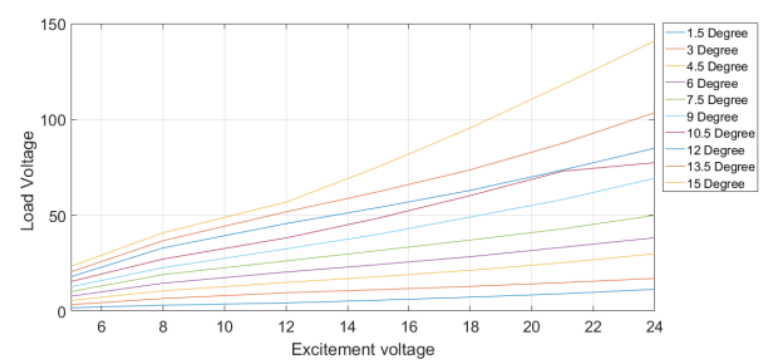

Fig 20. Generated Voltage with Excitation voltage variation.
The same test was performed in order to evaluate the operation of the machine with the lack of a phase, so that the phase $\mathrm{D}$ of the machine was disconnected from the circuit, the result can be seen in figure 21 and 22 .

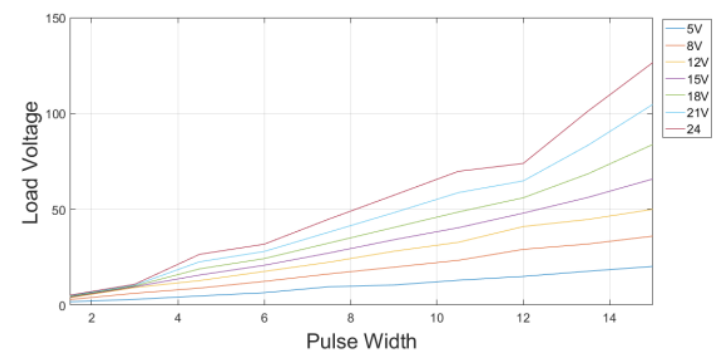

Fig. 21. Voltage generated with three phases - pulse width variation.

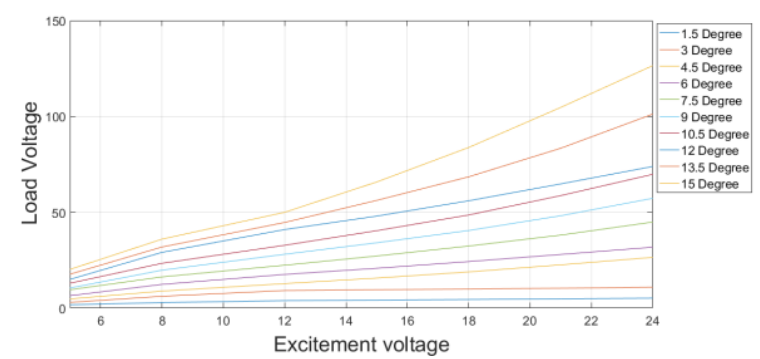

Fig. 22. Voltage generated with three phases - excitation voltage variation.

Using the various curves obtained, it was possible to trace a three-dimensional surface demonstrating the influence of the two analyzed parameters, pulse width and excitation voltage. Figure 23 shows the three-dimensional curve with the four phases, Figure 24 shows the three-dimensional curve when the machine was driven with 3 phases.

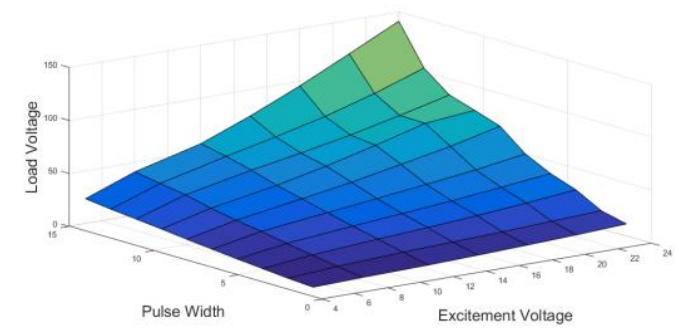

Fig. 23. Three-dimensional curve when the machine was driven with 4 phases.

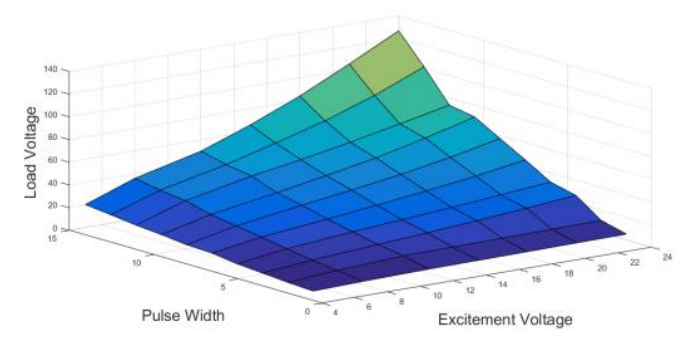

Fig. 24. Three-dimensional curve when the machine was driven with 3 phases.

For the purposes of comparison, it is noticed that as mentioned in [3], [4] and [5], the lack of one of the phases in the machine has a small impact on the generated voltage, for the same drive speed and the same load. 
Figure 25 shows some of the obtained curves, where the impact caused by the lack of one of the phases in the machine is evident. Figure 25 shows 7 curves, each having a different excitation voltage. Finally is the last two images compare the two results, since it is difficult to establish a comparison relation for different excitation voltages and pulse width at the angles. It was decided to establish the curves in a standard per unit [p.u], thus allowing to compare the curves independent of the excitation voltage adopted. The difference between the drive with all phases and the drive with the lack of one of the phases always remained below $15 \%$ for the conditions of drive, speed and load analyzed.

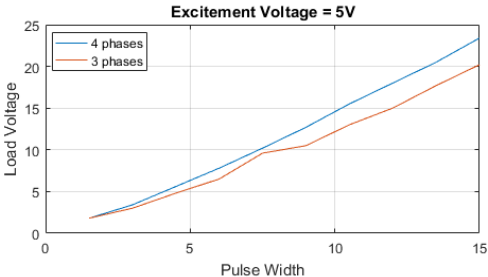

Excitement Voltage $=15 \mathrm{~V}$

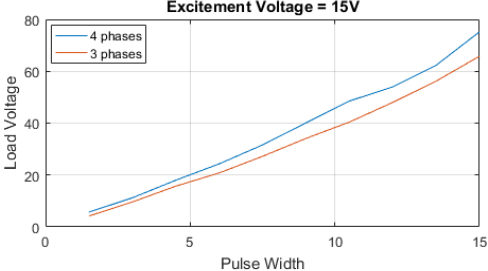

Excitement Voltage $=24 \mathrm{~V}$

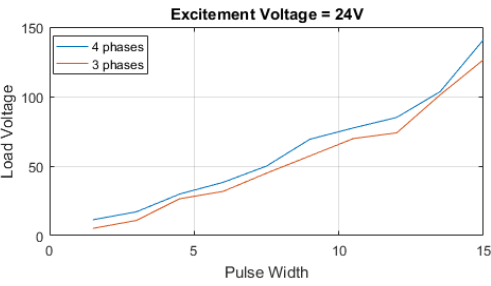

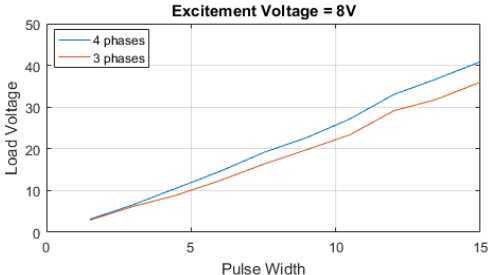

Excitement Voltage $=18 \mathrm{~V}$
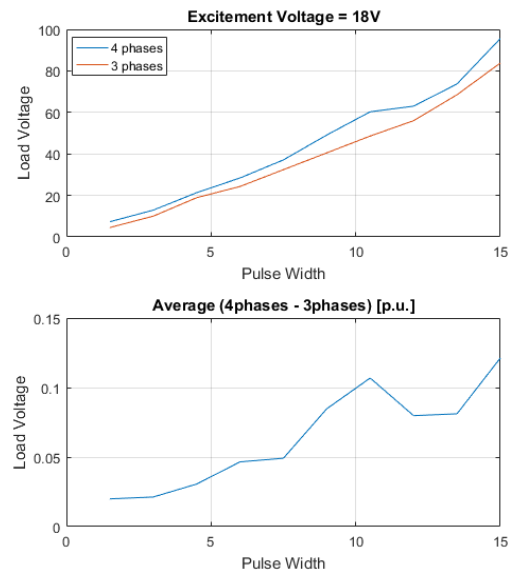

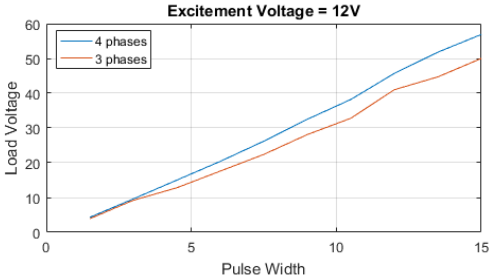

Excitement Voltage $=21 \mathrm{~V}$

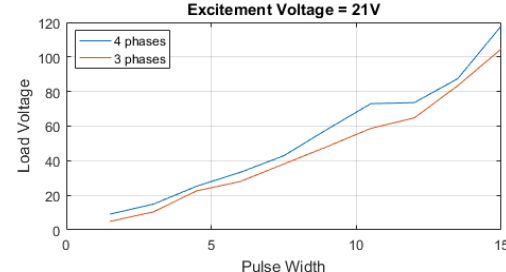

3D curve - (4phases - 3phases) [p.u.]

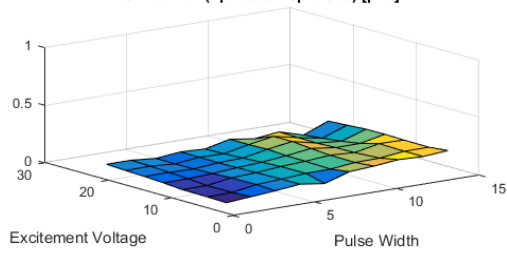

Fig. 24. Comparison between the drive with the four phases, and the lack of one of the phases.

\section{Conclusion}

The design and construction of an 8/6 Switched Reluctance Machine with a rated power of $3 \mathrm{CV}$ was done, a complete drive workbench was built, that will allow the drive and control of the machine enabling the development of various research about the machine applied to wind generator, Allowing consider intrinsic characteristics of wind generation, such as wind profiles. The bench still allow research on the activation and control of SRM as motor, motor-generator and generator for other applications, such as automotive and aerospace. These results indicate the viability of the proposed system. The developed bench will complement another bench developed in [1] and [2], tests will be carried out in order to compare the performance of the SRM 8/6 with the results obtained in [2] for the $6 \times 4$, and later the study of the best techniques of drives and forms of control.

\section{Acknowledgement}

The authors would like to thank Federal University of Uberlândia, Federal Institute of Education, Science and Technologia Goiás and National Industrial Learning Service SENAI Itumbiara, for the contribuition.

\section{References}

[1] R. Fidelis, "Development of an Experimental Platform to Drive the Switched Reluctance Machine", ICREPQ, 2016, ISNN 2172-038.

[2] R. Fidelis, "Voltage Behavior in the Switched Reluctance Generator Due to Different Speed Profiles Aimed at Use in Small Turbines", ICREPQ, 2017, ISNN 2172-038.

[3] G. Viajante, "Gerador a Relutância Variável em Conexão com a Rede elétrica para Injeção de Potência Ativa", in Proc. UFU2013, CDU:621.3.

[4] Moraes Filho, M. j., "Desenvolvimento de plataforma de acionamento digital para motor a relutância variável $8 / 6$ ", in Proc. UFU2017, CDU:621.3.

[5] COSTA, R. D. S. Análise, projeto e construção do motor monofásico à relutância chaveado: uma solução eficiente para cargas de potência fracionária. 2004. 158 (Mestre em engenharia elétrica). Faculdade de Engenharia Elétrica, Universidade Federal de Uberlândia

[6] D. Susitra, E. Jebaseli, A. Elisabeth, "Switched Reluctance Generator - Modeling Simulation, analysis and Control. A comprehensive Review", International Journal of Computer Application, 2010, Vol. $1 \mathrm{~N}^{\circ} 2$.

[7] T. Miller, "Eletronic Control of Switching Reluctance Machine", Newness Power Engineering Series, 2001. 272 pp

[8] A. Fleury, "Modelagem, Construção, Testes e Análise de Desempenho de um Gerador a Relutância Chaveado". UFU 2008, p258.

[9] A. Coelho, M. Aguiar, "Simulação, Projeto e Teste de um Gerador a Relutância Chaveado Trifásico 6x4”. USP 2001.

[10] D. Susitra, E. Jebaseli, A. Elisabeth, "Switched Reluctance Generator - Modeling Simulation, analysis and Control. A comprehensive Review", International Journal of Computer Application, 2010, Vol. $1 \mathrm{~N}^{\circ} 2$. 